\section{Treatment of chromite ore processing residue leachate contaminated water with modified nano-calcium hydroxy phosphate mineral surfaces}

\author{
JAI KISHAN RAJAK ${ }^{1}$, MR. NITIN KHANDELWAL, MS $^{2}$ \\ AND GOPALA KRISHNA DARBHA ${ }^{3}$ \\ ${ }^{1}$ Indian Institute of Science Education and Research-Kolkata \\ ${ }^{2}$ Indian Institute of Science Education and Research (IISER) \\ Kolkata \\ ${ }^{3}$ IISER Kolkata \\ Presenting Author: jksdx.9007@gmail.com
}

The alarming threats of groundwater pollution are of serious environmental concern for all living entities. Specifically, in developing nations, where due to lack of social awareness, most of the groundwater resources are continuously being polluted from the anthropogenic discharge of toxic metals from industries, landfills, and other diffused sources, resulting in a high level of contamination exceeding the permissible limits.

Improper dumping of wastes after ore processing can cause severe groundwater contamination and chromite ore processing residues (COPR) is one of them. COPR is a highly enriched source of $\mathrm{Cr}(\mathrm{VI})$, which due to its anionic nature, high toxicity, and mobility, contaminates the local groundwater aquifers $(1 ; 2)$. The major focus of this work is to modify eco-friendly nanocalcium hydroxy phosphate(HAP) mineral surface with materials like chitosan $(\mathrm{Ct})$ bio-polymer, layered double hydroxide(LDH), biochar(BC), and nano zero-valent iron(nZVI) for the removal of $\mathrm{Cr}(\mathrm{VI})$ from COPR contaminated groundwater samples(3).

These modified mineral surfaces were comparatively evaluated for the removal of chromate ions in both spiked chromium solutions and COPR leachate groundwater samples. Following this, batch and column experiments were performed. Fig.1 highlights the effect of time on $\mathrm{Cr}(\mathrm{VI})$ sorption capacity of various modified HAP mineral surfaces.

The results showed Cr(VI) sorption onto HAP-LDH from the solution with the fastest rate and highest efficiency compared to other modified surfaces (Fig 1a). Removal rate order was HAPLDH $>$ Ct-HAP-Fe ${ }^{0}>$ BC-HAP- $\mathrm{Fe}^{0}=$ HAP- $\mathrm{Fe}^{0}$ and in the case of COPR leachate groundwater sample (Fig.1b) higher rate of removal was observed in chitosan modified iron-enriched HAP $\left(\mathrm{Ct}-\mathrm{HAP}-\mathrm{Fe}^{0}\right)$. We also observed that the sorption capacity of LDH-HAP based mineral composites decreased drastically due to competitive metal sorption. Hence Ct-HAP- $\mathrm{Fe}^{0}$ shows a higher selectivity compared to other modified nano-mineral surfaces in highly complex leachate contaminated groundwater.

\section{References}

1. Khandelwal N, Behera MP, Rajak JK, Darbha GK. 2020. Clean Technol Envir 22:1015-24

2. Khandelwal N, Rajak J, Behera M, Darbha G. 2019. 9th IKONSWM Kinetics and isotherm studies for the removal of $\mathrm{Cr}$ (VI) from synthetic hard water using $\mathrm{FeO}$ Biochar composite

3. Rajak J, Khandelwal N, Behera M, Darbha G. 2021.

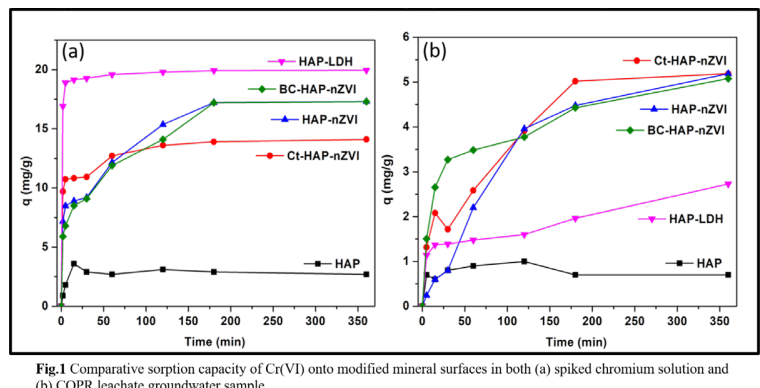

Fig. 1 Comparative sorption capacity of $\mathrm{C}$.
(b) COPR leachate groundwater sample. 